\title{
Synthesis of 2,6-trans-disubstituted 5,6-dihydropyrans from (Z)-1,5-syn-endiols
}

\author{
Eric M. Flamme ${ }^{1,2}$ and William R. Roush ${ }^{* 1,3}$
}

\section{Preliminary Communication}

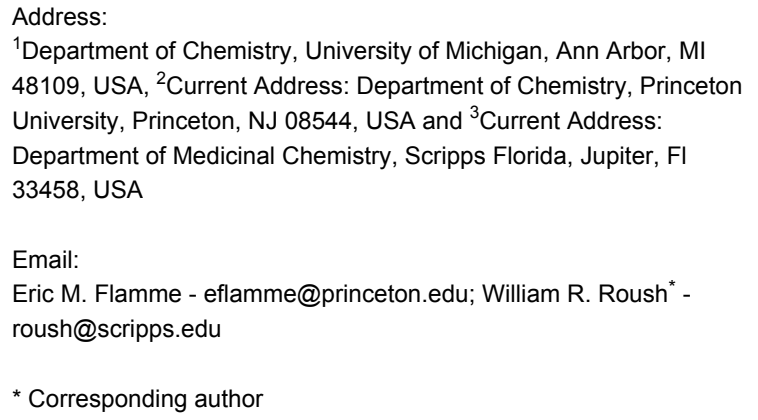

${ }^{1}$ Department of Chemistry, University of Michigan, Ann Arbor, MI 48109, USA, ${ }^{2}$ Current Address: Department of Chemistry, Princeton University, Princeton, NJ 08544, USA and ${ }^{3}$ Current Address: Department of Medicinal Chemistry, Scripps Florida, Jupiter, FI 33458, USA

Email:

Eric M. Flamme - eflamme@princeton.edu; William R. Roush ${ }^{*}$ roush@scripps.edu

* Corresponding author

Beilstein Journal of Organic Chemistry 2005, 1, No. 7. doi:10.1186/1860-5397-1-7

Received: 01 August 2005

Accepted: 26 August 2005

Published: 26 August 2005

(C) 2005 Flamme and Roush; licensee Beilstein-Institut. License and terms: see end of document.

\section{Abstract}

Certain (Z)-1,5-syn-diols 2 may be converted into 2,6-trans-5,6-dihydropyrans by using phosphonium salt 4 or phosphorane $\mathbf{5}$ as dehydrating agents. A more general four step procedure converts the (Z)-1,5-syn-endiols into enantiomeric dihydropyrans ent-3 via regioselective silylation of the allylic alcohol unit followed by mesylate formation and base-promoted nucleophilic displacement.

\section{Findings}

We recently reported a one-pot double allylboration reaction sequence which provides (Z)-1,5-syn-endiols from simple aldehyde starting materials with excellent diastereo- and enantioselectivity.[1] In connection with an ongoing natural product synthesis project, we were interested in developing methods to transform diols $\mathbf{2}$ into dihydropyrans $\mathbf{3}$ or the enantiomeric dihydropyrans ent-3 through complementary, regioselective cyclodehydration processes (Scheme 1).

2,6-Disubstituted dihydropyrans are common structural elements of many biologically active natural products.[2,3] A number of methods have been developed to synthesize substituted dihydropyrans including: (i) hetero-Diels-Alder cycloadditions,[4-7] (ii) electrophile-initiated alkylation of glycals,[8-11] (iii) ring closing metathesis,[12,13] (iv) vinylsilane cyclization of oxocarbenium ions, [14] and (v)

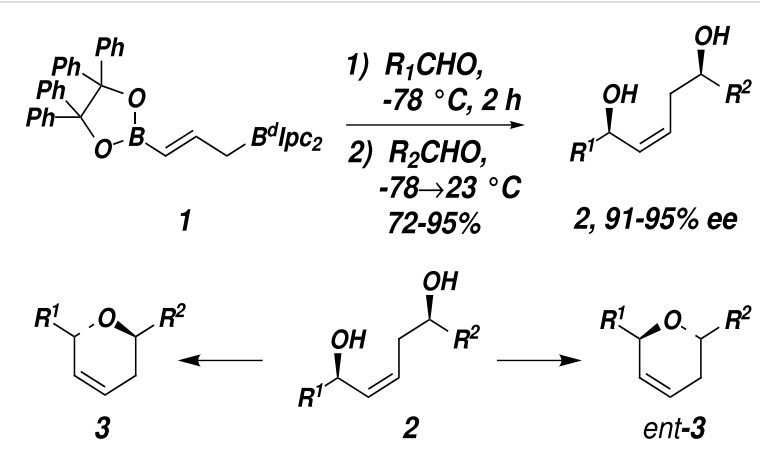

Scheme 1

intramolecular allylations.[15,16] However, we were unaware of any reports that describe the direct conversion of 1,5-diols containing an internal olefin such as $\mathbf{2}$ directly to 2,6-trans- 
disubstituted 5,6-dihydropyrans. Furthermore, there are only limited reports describing the stereoselective synthesis of related tetrahydropyrans through cyclodehydration of enantiopure 1,5-diols substrates.[17]

The challenge of synthesizing dihydropyrans $\mathbf{3}$ or ent-3 from 1,5-diols such as 2 lies in the differentiation of the two hydroxyl groups. Selective activation of the allylic alcohol in $\mathbf{2}$ as a leaving group followed by nucleophilic attack by the homoallylic alcohol will lead to dihydropyran 3. However, activation of the homoallylic alcohol followed by nucleophilic attack by the allylic alcohol will provide the enantiomeric dihydropyan ent-3. Cyclic ethers of various ring size have been synthesized by the cyclodehydration of diols through the use of oxyphosphonium salts and phosphorane reagents.[18-23] We reasoned that because the rate determining step of these cyclizations is believed to be the nucleophilic substitution step, selective formation of $\mathbf{3}$ should be possible owing to the superior leaving group ability of the activated allylic hydroxyl.[21]

Diol 2a $\left(\mathrm{R}_{1}=\mathrm{R}_{2}=\mathrm{CH}_{2} \mathrm{CH}_{2} \mathrm{Ph}\right)$ was used initially in the development of a suitable cyclodehydration protocol (Figure 1). Because the $R_{1}$ and $R_{2}$ substituents of $\mathbf{2 a}$ are identical, steric effects on the activation of the two hydroxyl groups are eliminated. Therefore, the enantioselectivity of the ring closing step will depend only on the relative rates of the competing cyclization processes leading to $\mathbf{3 a}$ and ent-3a. Initial attempts at cyclization of $\mathbf{2 a}$ using $\mathrm{Ph}_{3} \mathrm{P}$ and diethyl azodicarboxylate or $\mathrm{Ph}_{3} \mathrm{P}-\mathrm{CCl}_{4}$ were low yielding (entries 1,2).[22] Interestingly, small amounts of the 2,6-cis-disubstituted dihydropyran $\mathbf{6 a}$ were detected under these conditions, suggesting the interven- tion of a competitive double inversion process or a carbocationmediated cyclization process. In order to avoid the presence of nucleophilic counter ions, we turned to the use of phosphonium salt $\mathbf{4}$ and phosphorane 5 as the cyclodehydration reagents (Scheme 2).[24,25]

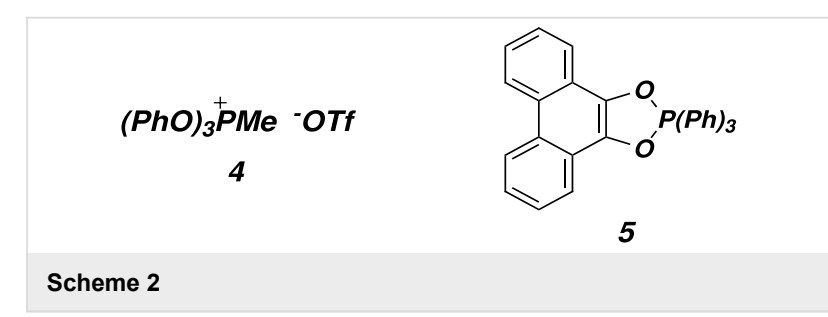

Treatment of diol $2 \mathrm{a}$ with 4 in acetonitrile $(0.05 \mathrm{M})$ at $0^{\circ} \mathrm{C}$ and warming slowly to $23^{\circ} \mathrm{C}$ provided a $9: 1$ mixture of trans and cis dihydropyrans 3a and 6a in 65\% combined yield (entry 3). We speculated that the cis isomer might arise via formation of an allylic cation (perhaps facilitated by acid formed by competitive elimination of the oxyphosphonium salt during the reaction). Accordingly, the trans/cis ratio was improved to $13: 1$ by addition of 2,6-tert-butyl-4-methyl-pyridine as an acid scavenger (entry 4). Ultimately, we found that use of $\mathrm{CH}_{2} \mathrm{Cl}_{2}$ as the solvent and $\mathrm{Et}_{3} \mathrm{~N}$ as base provided 3a in 78\% yield with 20:1 trans/cis selectivity (entry 5). However, chiral HPLC analysis indicated that 3a from entry 5 had an enantiomeric excess of only $25 \%$ e.e. while the enantiomeric purity of the starting diol 2a was $91 \%$ e.e.

This result suggests that the selectivity for displacement of the two hydroxyl groups of $\mathbf{2 a}$ is only ca. $2: 1$ under these conditions. Examination of molecular models indicates that in order

\begin{tabular}{|c|c|c|c|c|c|c|c|c|}
\hline \multicolumn{2}{|r|}{$2 a, 91 \%$ ee } & \multicolumn{2}{|c|}{$\begin{array}{c}\text { cyclodehydratio } \\
\text { conditions } \\
\text { (see Table) }\end{array}$} & \multicolumn{2}{|l|}{$3 a$} & + & & \multirow[b]{2}{*}{ \% e.e. } \\
\hline entry & reagents (equiv) & conc. & time, $h$ & solvent & temp, ${ }^{\circ} \mathrm{C}$ & yield (\%) & $3 a: 6 a$ & \\
\hline 1 & $\mathrm{PPh}_{3}(1.5), \mathrm{CCl}_{4}$ & 0.5 & 24 & $\mathrm{CCl}_{4}-\mathrm{CH}_{2} \mathrm{Cl}_{2}$ & 55 & 36 & $10: 1$ & $N D$ \\
\hline 2 & $P P h_{3}(1), D E A D(1.3)$ & 0.4 & 24 & $\mathrm{CHCl}_{3}$ & 23 & 32 & ND & $N D$ \\
\hline 3 & $4(1.2)$ & 0.05 & 8 & $\mathrm{CH}_{3} \mathrm{CN}$ & $0 \rightarrow 23$ & 65 & $9: 1$ & $N D$ \\
\hline 4 & 4 (1.2), DTBMPyr (2.1) & 0.04 & 8 & $\mathrm{CH}_{3} \mathrm{CN}$ & $0 \rightarrow 23$ & 68 & 13: 1 & $N D$ \\
\hline 5 & $4(1.5), E t_{3} N(2)$ & 0.08 & 8 & $\mathrm{CH}_{2} \mathrm{Cl}_{2}$ & $0 \rightarrow 23$ & 78 & $20: 1$ & 25 \\
\hline 6 & $4(1.5), E t_{3} N(2)$ & 0.08 & 24 & $\mathrm{CH}_{2} \mathrm{Cl}_{2}$ & -35 & 52 & $20: 1$ & 60 \\
\hline 7 & $4(1.5), E t_{3} N(2)$ & 0.08 & 24 & $\mathrm{CH}_{2} \mathrm{Cl}_{2}$ & -78 & $<50$ & $20: 1$ & 90 \\
\hline 8 & $4(1.5), E t_{3} N(2)$ & 0.08 & 24 & hexanes & $0 \rightarrow 23$ & 78 & $24: 1$ & 46 \\
\hline 9 & $5(1.5), E t_{3} N(2)$ & 0.1 & 18 & toluene & 80 & 71 & trans & 50 \\
\hline
\end{tabular}

$N D=$ not determined; DTBMPyr $=2,6-t$ Butyl-4-Me-pyridine

Figure 1: Cyclodehydration of diol 2a 


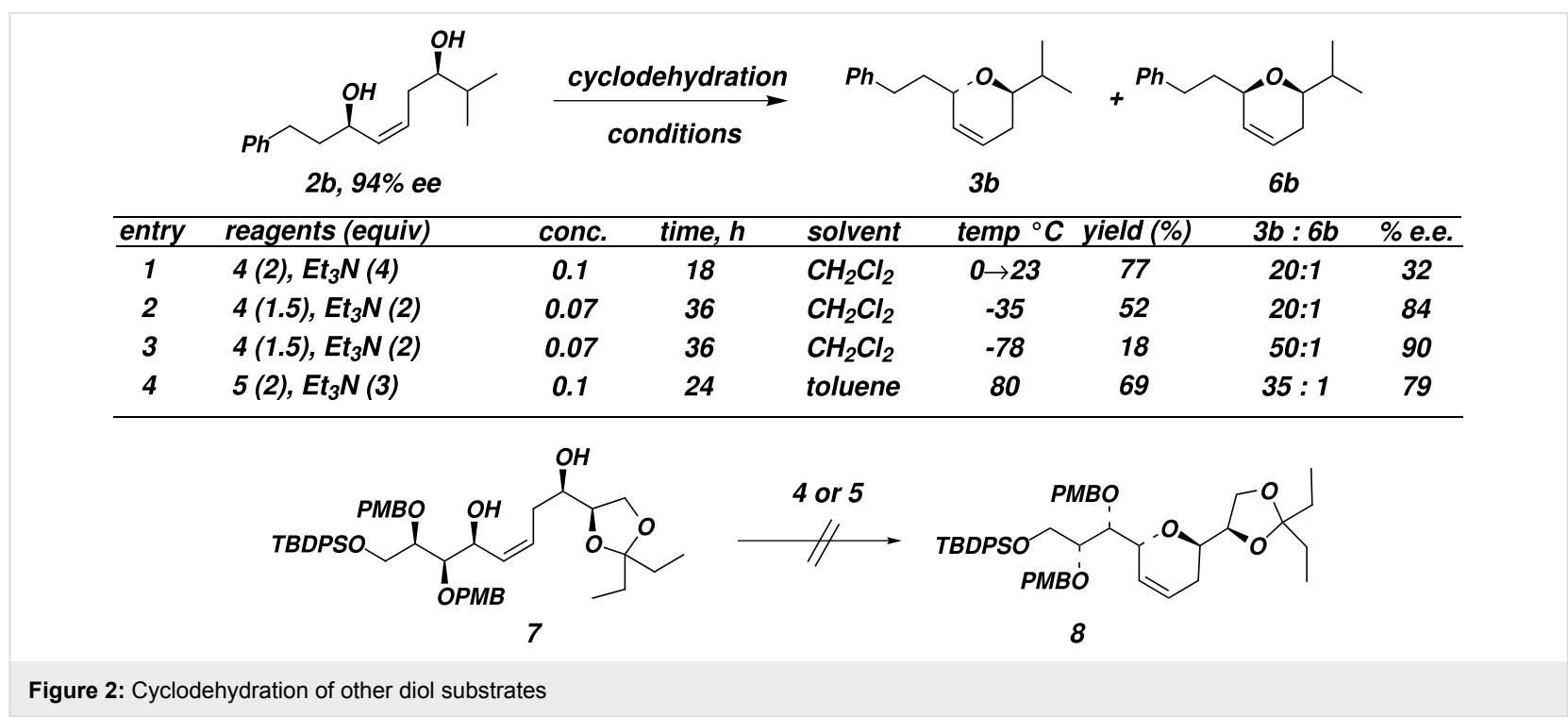

for the activated allylic alcohol to be displaced in this intramolecular substitution process, the allylic C-O bond substantially deviates from coplanarity with the adjacent $\pi$-system. Therefore, the difference in relative rates of displacement of the two activated hydroxyl groups is much less than originally anticipated. The enantioselectivity could be increased to $90 \%$ by lowering the reaction temperature to $-78^{\circ} \mathrm{C}$, but the yield of dihydropyran 3a was reduced to less than $50 \%$ (entry 7 ).

Dehydration of 2a with phosphorane 5 in toluene at $80^{\circ} \mathrm{C}$ in the presence of triethylamine provided exclusively trans dihydropyran $3 \mathrm{a}$ in a yield of $71 \%$ and $50 \%$ e.e. (Figure 1 , entry 9). Attempts to increase the enantioselectivity of the reaction by lowering the reaction temperature were thwarted by the poor solubility profile of $\mathbf{5}$. Changing the solvent from toluene to hexanes, THF, or NMP also did not significantly impact the $\%$ e.e.

Attempts to extend these results to other systems met with limited success (Figure 2). We anticipated that the regioselectivity of dehydration of a substrate like $\mathbf{2 b}$ in which the homoallylic hydroxyl is more sterically hindered than the allylic one would be improved relative to 2 a. Indeed, the cyclodehydration of $\mathbf{2 b}$ with phosphorane $\mathbf{5}$ in toluene at $80^{\circ} \mathrm{C}$ proceeded with ca. $9: 1$ regioselectivity (entry 4), and use of the phosphonium salt 4 at $-35^{\circ} \mathrm{C}$ also gave reasonably good results $\left(84 \%\right.$ e.e.). However, all attempts to dehdyrate the $\alpha, \alpha^{\prime}$ oxygenated diol $\mathbf{7}$ with either $\mathbf{4}$ or $\mathbf{5}$ were unsuccessful.

Given that the cyclodehydration reactions of diol substrates were complicated by selectivity and reactivity issues (s Figure 1 and Figure 2), we turned to an alternative strategy which would not rely on chemoselectivity in the cyclodehydration step. To this end, mesylates $\mathbf{1 1}$ were synthesized (Scheme 3).

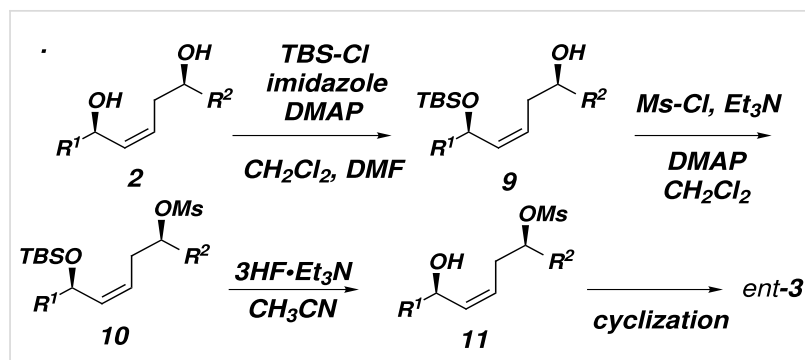

Scheme 3

Treatment of 1,5-diols 2 with TBS-Cl and imidazole effects selective protection of the allylic alcohol (Scheme 4). The mono-TBS protected 9 is the major product in all cases except when $2 \mathbf{f}$ was used as the substrate; in this case, the allylic hydroxyl is more hindered than the homoallylic hydroxyl, which is silylated preferentially. The homoallylic TBS ethers 12 and the bis-TBS ethers $\mathbf{1 3}$ can be conveniently recycled. The origin of the regioselectivity of the selective silylation of 1,5-diols 2 is unknown at present.

Subsequent treatment of mono-TBS ethers 9 with methanesulfonyl chloride $(\mathrm{MsCl})$ followed by deprotection of the TBS ether by using $3 \mathrm{HFEt}_{3} \mathrm{~N}$ afforded mesylates 11 (80- $\geq 95 \%$ yield). Treatment of mesylate 11a with 1 equivalent of potassium tert-butoxide in tert-BuOH $(0.01 \mathrm{M})$ between $40-50$ ${ }^{\circ} \mathrm{C}$ provided ent-3a in $75 \%$ yield and 10:1 selectivity for the dihydropyran product and a diene resulting from an undesired E2 elimination (Figure 3, entry 1).[26,27] This result was particularly gratifying since Thomas has reported that attempts 


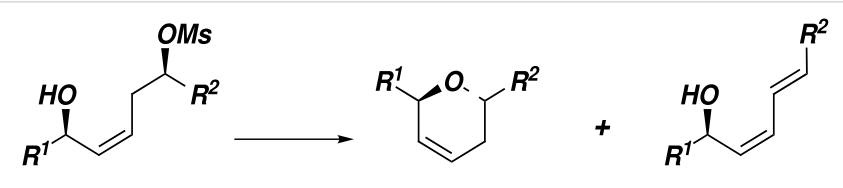

11

ent-3

14

\begin{tabular}{|c|c|c|c|c|c|}
\hline ubs & $t$ & conditions & product & $3: 14$ & yield \\
\hline $11 a$ & KO & $t-B$ & $a$ & $90: 10$ & \\
\hline $11 a$ & $\left(\mathrm{Bu}_{3} \mathrm{Sn}\right)_{2} \mathrm{O}$ & $D M F, 80^{\circ} \mathrm{C}$ & ent-3a & $99: 1$ & $80 \%$ \\
\hline $11 b$ & $K O t B u$ & $t-B u O H, 45^{\circ} \mathrm{C}$ & ent-3b & $80: 20$ & $80 \%$ \\
\hline $11 b$ & $\left(\mathrm{Bu}_{3} \mathrm{Sn}\right)_{2} \mathrm{O}$ & $D M F, 80^{\circ} \mathrm{C}$ & ent-3b & $88: 12$ & $76 \%$ \\
\hline $11 c$ & KOtBu & $t-B u O H$ & ent & $80: 20$ & $70 \%$ \\
\hline $11 c$ & $\left(\mathrm{Bu}_{3} \mathrm{Sn}\right)_{2} \mathrm{O}$ & ${ }^{\circ} \mathrm{C}$ & ent-3c & $83: 17$ & $81 \%$ \\
\hline $11 d$ & KOtBu & $t-B u O H, 45^{\circ} \mathrm{C}$ & ent-3d & $78: 22$ & $78 \%$ \\
\hline $11 d$ & $\left(\mathrm{Bu}_{3} \mathrm{Sn}\right)_{2} \mathrm{O}$ & $75^{\circ} \mathrm{C}$ & ent-3d & $99: 1$ & $82 \%$ \\
\hline $11 e$ & KOtBu & $t-B u O H, 45^{\circ} \mathrm{C}$ & ent-3e & $50: 50$ & $48 \%$ \\
\hline $11 e$ & $\left(B u_{3} \mathrm{Sn}\right)_{2} \mathrm{O}$ & $D M F, 70^{\circ} \mathrm{C}$ & ent-3e & $72: 28$ & $72 \%$ \\
\hline $11 f$ & KOtBu & $t-B u O H, 45^{\circ} \mathrm{C}$ & ent-3f & $75: 25$ & $60 \%$ \\
\hline $11 f$ & $\left(\mathrm{Bu}_{3} \mathrm{Sn}\right)_{2} \mathrm{O}$ & $D M F, 70^{\circ} \mathrm{C}$ & ent-3f & $99: 1$ & $90 \%$ \\
\hline
\end{tabular}

Figure 3: Cyclization of Hydroxymesylates 11

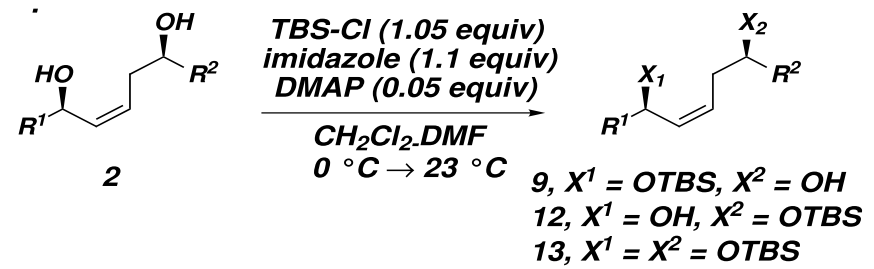

\begin{tabular}{ccccc} 
Substrate & 9 & 12 & 13 & 2 (recovered) \\
\hline $2 a$ & $50 \%$ & $5 \%$ & $13 \%$ & $25 \%$ \\
$2 b$ & $72 \%$ & $3 \%$ & $8 \%$ & $11 \%$ \\
$2 c$ & $45 \%$ & $11 \%$ & $23 \%$ & $15 \%$ \\
$2 d$ & $50 \%$ & $7 \%$ & $8 \%$ & $28 \%$ \\
$2 e$ & $63 \%$ & $4 \%$ & $5 \%$ & $31 \%$ \\
$2 f$ & $10 \%$ & $24 \%$ & $1 \%$ & $60 \%$
\end{tabular}<smiles>COC[C@H](O)C/C=C\[C@H](O)CCCCCOc1ccccc1</smiles>

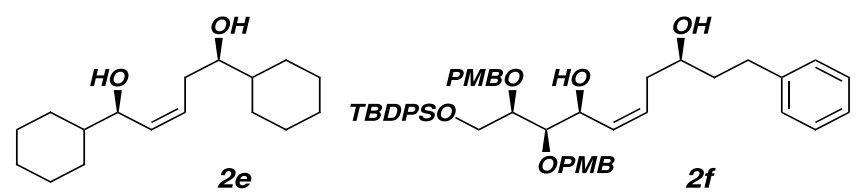

Scheme 4

to cyclized suitably activated 1,5-diol substrates under basic conditions did not afford dihydropyran products.[28] It was necessary to carry out the reactions under dilute conditions in order to minimize elimination to diene $\mathbf{1 4}$. However, increased steric demands about the mesylate (11b) or the allylic alcohol (11c) led to increased amounts of elimination, although the isol- ated yields of the dihydropyrans $\mathbf{3 b}$ and $\mathbf{3} \mathbf{c}$ were acceptable (Figure 3). Treatment of mesylate 11e containing cyclohexyl groups flanking both the allylic alcohol and the mesylate gave a 1:1 mixture of ent-3e and 14e. $\alpha$-Oxygenated substrates $11 \mathrm{~d}$ and 11f cyclized with $3.5: 1$ and $3: 1$ selectivity under these conditions. 
It is known that tributylstannyl ethers are decent nucleophiles and are considerably less basic than oxanions.[29,30] Indeed, we found that elimination products $\mathbf{1 4}$ could be suppressed by treatment of alcohols 11 with $\left(\mathrm{Bu}_{3} \mathrm{Sn}\right)_{2} \mathrm{O}$ in benzene followed by heating the resulting tributylstannyl ethers in DMF at $80^{\circ} \mathrm{C}$ (Figure 3). In this way, selectivity for the formation of dihydropyran ent-3 versus elimination could be increased up to 99:1 for substrates 11a, 11d, and 11f. All other substrates examined also showed improved selectivity for pyran formation, and in all cases the dihydropyran ent-3 was obtained in at least $72 \%$ yield.

In summary, the scope of cyclodehydration reactions of (Z)-1,5syn-diols $\mathbf{2}$ to give the the targeted dihydropyrans $\mathbf{3}$ using $\mathbf{4}$ and 5 as dehydrating reagents in a one-pot procedure is limited to substrates that lack oxygen substituents at positions adjacent to the leaving group. Acceptable enantioselectivity can be achieved by performing these cyclodehydration reactions at low temperatures. However, a much more general procedure for synthesis of the enantiomeric dihydropyrans ent-3 involves the stannyl ether mediated cyclization of hydroxy mesylates $\mathbf{1 1}$. This method relies on a selective silylation of the homoallylic alcohol, and represents a new route to access 2,6-trans-disubstituted 5,6-dihydropyrans. Application of this methodology in natural products synthesis will be reported in due course.

\section{Supporting Information Available}

Experimental procedures and full spectroscopic data for all new compounds (42 pages).

\section{Supporting Information}

\section{Supporting Information File 1}

Experimental details

[http://www.beilstein-journals.org/bjoc/content/

supplementary/1860-5397-1-7-S1.doc]

\section{Supporting Information File 2}

NMR spectra

[http://www.beilstein-journals.org/bjoc/content/ supplementary/1860-5397-1-7-S2.pdf]

\section{Acknowledgments}

Financial support was provided by the National Institutes of Health (GM 38436).
2. Faulkner, D. J. Nat. Prod. Rep. 2000, 17, 7-55. doi:10.1039/a809395d

3. Norcross, R. D.; Paterson, I. Chem. Rev. 1995, 95, 2041-2114. doi:10.1021/cr00038a012

4. Dossetter, A. G.; Jamison, T. F.; Jacobsen, E. N. Angew. Chem., Int. Ed. 1999, 38, 2398-2400. doi:10.1002/(SICI)1521-3773(19990816)38:16<2398::AID-ANIE2398>3 .0.CO;2-E

5. Lubineau, A.; Auge, J.; Lubin, N. Tetrahedron 1993, 49, 4639-4650. doi:10.1016/S0040-4020(01)81292-8

6. Danishefsky, S. J.; Selnick, H. G.; Zelle, R. E.; DeNinno, M. P. J. Am. Chem. Soc. 1988, 110, 4368-4378. doi:10.1021/ja00221a043

7. Danishefsky, S. J.; DeNinno, M. P. Angew. Chem., Int. Ed. Engl. 1987, 26, 15-23. doi:10.1002/anie.198700151

8. Steinhuebel, D. P.; Fleming, J. J.; Du Bois, J. Org. Lett. 2002, 4, 293-295. doi:10.1021/ol010273e

9. Ferrier, R. J. Top. Curr. Chem. 2001, 125, 153-175.

10. Levy, D. E.; Tang, C. The Chemistry of C-Glycosides; Pergamon Press: Tarrytown, 1995; Vol. 13.

11. Postema, M. H. D. C-Glycoside Synthesis; CRC Press: Boca Raton, 1995.

12. Mulzer, J.; Hanbauer, M. Tetrahedron Lett. 2000, 41, 33-36. doi:10.1016/S0040-4039(99)02021-3

13. Burke, S. D.; Ng, R. A.; Morrison, J. A. J. Org. Chem. 1998, 63, 3160-3161. doi:10.1021/jo980163u

14. Semeyn, C.; Blaauw, R. H.; Hiemstra, H.; Speckamp, W. N. J. Org. Chem. 1997, 62, 3426-3427. doi:10.1021/jo970369f

15. Huang, H.; Panek, J. S. J. Am. Chem. Soc. 2000, 122, 9836-9837. doi:10.1021/ja002087u

16. Roush, W. R.; Dilley, G. J. Synlett 2001, 955-959. doi:10.1055/s-2001-14632

17. Chikashita, H.; Hirao, K.; Itoh, K. Bull. Chem. Soc. Jpn. 1993, 66, 1738-1742.

A search of the literature found only one report.

18. Hughes, D. L. Org. Prep. Proced. Int. 1996, 28, 127-164.

19. Hendrickson, J. B.; Hussoin, M. S. Synlett 1990, 423-424. doi:10.1055/s-1990-21115

20. Denney, D. B.; Denney, D. Z.; Gigantino, J. J. J. Org. Chem. 1984, 49, 2831-2832. doi:10.1021/jo00189a044

21. Robinson, P. L.; Barry, C. N.; Bass, S. W.; Jarvis, S. E.; Evans, S. A., Jr. J. Org. Chem. 1983, 48, 5396-5398. doi:10.1021/jo00174a059

22. Carlock, J. T.; Mack, M. P. Tetrahedron Lett. 1978, 19, 5153-5156. doi:10.1016/S0040-4039(01)85836-6

23. Castro, B. R. Org. React. 1983, 29, 1-162.

24. Phillips, D. I.; Szele, I.; Westheimer, F. H. J. Am. Chem. Soc. 1976, 98, 184-189. doi:10.1021/ja00417a029

25. Kelly, J. W.; Robinson, P. L.; Evans, S. A., Jr. J. Org. Chem. 1986, 51, 4473-4475. doi:10.1021/jo00373a026

26. Cink, R. D.; Forsyth, C. J. J. Org. Chem. 1997, 62, 5672-5673. doi:10.1021/jo9708755

27. Boivin, T. L. B. Tetrahedron 1987, 43, 3309-3362. doi:10.1016/S0040-4020(01)81626-4

28. Maguire, R. J.; Thomas, E. J. J. Chem. Soc., Perkin Trans. 1 1995, 2477-2485. doi:10.1039/p19950002477

29. Davies, A. G. Organotin Chemistry; Wiley-VCH: Weinheim, 1997.

30. David, S.; Hanessian, S. Tetrahedron 1985, 41, 643-663. doi:10.1016/S0040-4020(01)96443-9

\section{References}

1. Flamme, E. M.; Roush, W. R. J. Am. Chem. Soc. 2002, 124,

13644-13645. doi:10.1021/ja028055j 


\section{License and Terms}

This is an Open Access article under the terms of the Creative Commons Attribution License

(http://creativecommons.org/licenses/by/2.0), which permits unrestricted use, distribution, and reproduction in any medium, provided the original work is properly cited.

The license is subject to the Beilstein Journal of Organic Chemistry terms and conditions:

(http://www.beilstein-journals.org/bjoc)

The definitive version of this article is the electronic one which can be found at:

doi:10.1186/1860-5397-1-7 